\title{
0357 USE OF MATCHED COHORT STUDIES TO ESTIMATE THE EFFECTIVENESS OF CHILD RESTRAINTS
}

T M Rice*, C Anderson Correspondence: Department of Environmental Health Sciences, Safe Transportation Research \& Education Center, 2614 Dwight Way, \#7374 Berkeley, CA 94720, USA

10.1136/ip.2010.029215.357

Background Many researchers believe that only child occupants should be used in matched cohort studies of child restraint effectiveness. The objective of this study was to explore the performance of the matched cohort study design in estimating associations between child restraints and other occupant characteristics with death risk.

Methods We conducted Monte Carlo data simulations to represent 10000 collision-involved vehicles carrying a mix of children and adults. We set the effects of age, seating position, adult seat belt use, child seat belt use and child safety to known values. We created an association between child restraint use and collision severity to confound the restraintdeath risk association. Death risk ratios were estimated with conditional Poisson regression.

Results Estimated risk ratios were unbiased and precise for all variables in the models, including those relevant only to children. The average child safety seat risk ratio was 0.30 (true value 0.3 ) and the average child seat belt risk ratio was 0.50 (true value 0.5). The lower baseline death risk for children as also correctly estimated ( 0.75 , true value 0.75$)$.

Conclusions These findings demonstrate that matched cohort studies, together with conditional regression, can be used to estimate associations between occupant characteristics, including child restraint use and the death risk. Results were unconfounded by crash severity and were not reliant on an assumption of equal baseline risk of occupants of each vehicle. The use of child-only matched sets of data resulted in a notable loss of information and less precise estimates of effect. 